in the sea, has naturally been regarded as worthless from the zonal or even correlative aspect, and thus has Schuchert sought to explain the critical attitude of Vaughan and others. The whole point of the detailed work, however, is its intensiveness, as is the case with petrographic research under similar conditions, and the fact that local assemblages, rather than precise species, constitute the basis of study; zoning is effected by recognition of slight variations in morphology, ornament, etc., by creating new species or new varieties much as in the case of the ammonites previously cited. The question of percentage of living Foraminifera in any faunule, a point on which Vaughan has laid some stress, is entirely subordinated by the specialists to the question of the actual species present and their manner of combination in any particular faunule. According to Cushman, "the time value of forams ... is entirely dependent on this splitting (of species), for putting together species which are of short range into one long one would entirely defeat the purpose of close correlation."

Mesozoic and Cainozoic Bryozoa have long been recognised as important indexes of horizon, though in the Gulf Coast oil-field region they are of far less frequent occurrence than the Foraminifera. Schuchert has no doubt whatever regarding their true value for subsurface correlation, and advocates strongly their use on the basis of Canu and Bassler's classical work. According to Bassler, of the two orders of Bryozoa, namely, Cyclostomata and Cheilostomata, the former has potentially little value in sub-surface work, from the fact that precise diagnosis rests on the preservation of the ovicell, almost an impossibility with oilwell samples. The Cheilostomata, however, can be determined from minute fragments and all characteristics can be ascertained, even though only a few individuals or zoceia are preserved. They tend to indicate limited time-zones over wide areas, and various structures shown on the zocecium are significant of depth of water, temperature, nature of ocean bottom and character of marine habitat. Add to this that the calcareous structures are generally highly ornate and variable in that ornament, and the possibility of treating them on the same intensive lines as the Foraminifera is apparent. Canu and Bassler describe 742 forms of North American Early Tertiary Bryozoa in their work, many of which are beautifully illustrated.

Ostracods, as we now realise from the Wealden formations of Great Britain, are potentially valuable as time-indicators, though here again much intensive work has yet to be done before they are fully appreciated. Analysis of well-cuttings from the Gulf Coast region reveals their presence and significance, and Schuchert has directed attention to the highly ornate forms of the valves of these minute crustacea, but the Texan species have yet to be worked out. Ulrich and Bassler have demonstrated their potentiality as guide-fossils to limited portions of certain American palæozoic formations, which research at least forms an adequate basis of future investigation.

In so far as Radiolaria, Diatomacea, sponge spicules and echinid spines are concerned in sub-surface work, at the present time we must regard them in much the same light as petrographers regard sporadically occurring mineral species in oil-well samples: of local and possibly direct differential or confirmatory value. As Schuchert says, "each worker must learn what local dependence can be placed upon these isolated occurrences."

Thus it is clear that while a degree of scepticism regarding the use of micro-organisms in stratigraphical correlation may still be maintained on certain technical grounds, the results so far achieved by the American school are worthy of general attention. It is yet one further example of how much the pure science may owe to one phase of its economic application. Readers are referred to the volumes of the American Association of Petroleum Geologists for 1924 and 1925 for several important papers in connexion with the above, and particularly to Schuchert's excellent summary of the subject in volume 8 , I924, pp. 539-553; these volumes are available for reference in the Science Library at South Kensington.

\title{
Sterility and Rejuvenation.
}

$\mathrm{I} \mathrm{T}$ has been known for a long time that the sexual activity and characteristics of the individual depend on the presence of the sexual glands in an actively functioning condition. Their removal or atrophy as in old age leads to loss of sexual vigour together with changes in the secondary sex characters which may result in the development of a neutral individual, or even in the assumption of certain of the characteristics of the opposite sex, according to the species studied.

Various methods have been used for supplementing a deficiency in the individual's own secretions, such as grafting glands from another member of the same or an allied species, the injection of extracts of the glands, and in males, the ligature of the duct which conveys the sperm from the testes to the urethra: the latter operation (vasoligation) has been performed on the assumptions that the secretions on which the secondary sex characters depend arise from the interstitial cells of the sex glands, and that ligature of the duct, by causing atrophy of the sperm-producing cells, will allow the interstitial cells to hypertrophy, owing to the increased space and nutriment provided. The return of the secondary sexual characteristics does not imply a return of fertility, since, for the latter, the sex glands themselves must be actively functioning in situ: that is, atrophied or diseased glands must be reactivated. Grafting alone, therefore, will not restore fertility, except, perhaps, in the case of the female, unless the aninal's own sex glands are also reactivated or rejuvenated by means of the secretions from the graft.

Sterility in the female can be caused not only by atrophy (or removal) of the ovaries, but also by persistence of the corpora lutea. During pregnancy these bodies persist and prevent ovulation, and occasionally this occurs apart from pregnancy as a pathological phenomenon and produres sterility, fertility being restored by their removal. It is of interest, in connexion with recent work on the isolation of an

NO. 2946, VOL. I I 7 ] 
ovarian hormone, that W. P. Kennedy (Quart. Journ. Physiol., I925, vol. I5, p. I03) has found that cold saline extracts of fresh frozen or dried corpora lutea, intravenously injected, prevent ovulation in rabbits: the effect persists for several months after a number of injections. Continued injections cause degenerative changes, not only in the ovaries, where the number of Graafian follicles is reduced, these changes being probably specific, in part at any rate, but also in the liver and adrenal glands, where the effect may be due to the injection of toxic foreign proteins, or alternatively to changes in the carbohydrate metabolism produced by the degeneration of the ovaries. Since extracts of ovarian tissue are being used for the production of the opposite effect, namely, the return of fertility and the secondary sexual characteristics, it is obvious that care should be taken to use only glands in which there are no corpora lutea, or from which these bodies have been removed, for the preparation of such extracts.

The main interest of some recent work by Steinach and his collaborators on the ovarian hormone appears to lie in the true reactivation or rejuvenation of the ovaries of senile animals (E. Steinach, H. Heinlein, and 13. P. Wiesner, Akad. d. Wissensch., Wien, I925, No. r9, p. .189). These investigators have injected extracts of ovary and placenta into animals castrated both before and after puberty, and into senile specimens, using the vaginal smear method to follow the return or not of the œstrual cycle. Extracts from either source favour the development of the secondary sexual characteristics, but only those from the ovary arouse the sexual cycle. In all cases the normal condition of the animal is restored. The effects observed are produced by only a few injections in young animals, and occur within a few days in both rats and guinea-pigs. The fertility of stock female rats ceases when they are about eighteen months old, and the sexual cycle vanishes a few months later. Injections now restore their vigour and produce a reappearance of the cestrual cycle, the latter continuing regularly after the injections have been discontinued: in other words, the ovaries are reactivated. The next step should be the application of a purified ovarian extract in human therapeutics.

Most of the work on rejuvenation has been performed on mammals. Crew has turned his attention to birds. He has found (F. A. E. Crew, Proc. Roy. Soc. Edin., I925, vol. 45 , p. 249) that unilateral vasoligation in senile cocks is not accompanied by any rejuvenating effect. The only change observed microscopically in the testes was continuation of the degenerative processes seen to be occurring at the time of the operation in a preparation of a portion of the testis on the side of the ligature removed for histological study. No change was observed in their plumage. On the other hand, this author has been successful in obtaining rejuvenation in birds of both sexes by the administration of dried thyroid (ibid. p. 252). The doses given corresponded to $0.2-0.8 \mathrm{mgm}$. iodine daily. The first effect noted was moulting by all birds, and this was followed by an increased egg production by the females, the eggs being fertilised by the males ; none of the former, however, became broody. The plumage of cock-feathered cocks became henny, but that of the hens and of henfeathered cocks remained almost unchanged. The author considers that these results can be explained on the assumption that the sexual glands exert their influence on the plumage, not directly, but by means of an action upon the thyroid. Thus there are two classes of fowls : those whose thyroid responds to a certain low degree of stimulation from the testes with the production of cock-feathering, and to a higher degree of stimulation from the ovaries with the production of hen-feathering; and those whose thyroid responds to the greater degree to testicular stimulation, the cocks thus being henfeathered. The difference between the thyroids of the two classes is a genetic one. The administration of thyroid can only produce a marked effect on those birds the thyroid gland of which is not normally fully stimulated, that is, cocks with cock-feathering.

\section{Obituary.}

\section{Prof. K. LHoták.}

$\mathrm{O}^{\mathrm{N}}$ January 27 there died in Prague, at the relatively early age of forty-nine years, Dr. Kamil Lhoták, professor of pharmacology and pharmacognosy and director of the institute for the said sciences in the Charles' (Bohemian). University. Prof. Lhoták published many scientific investigations in physiology, in which he had a sound training; in pharmacology and pharmacognosy, but the most prominent are his researches on the active substances of digitalis (digitalin, digitoxin). Lhoták also published the first Bohemian treatise on pharmacognosy (I908) ; but especially noteworthy is his voluminous "Pharmacology" (I924), including also the theory and art of prescribing.

As a teacher Prof. Lhoták turned his attention to the practical work of students in his laboratory, based on his experience in England. But one of his greatest merits, from the international point of view, is that he gave an impulse to the reprinting of the scientific papers of the Bohemian genius Ian Purkyne (Purkinje), who founded the first physiological research laboratory in Germany, so that his researches, scattered in less accessible journals, could become accessible to the scientific world. They are published by the Bohemian Society of Medicine, together with two volumes of the very interesting correspondence of. a many-sided scientist. Prof. Lhoták was not only of a real, deep scientific nature, but also a great connoisseur of painting, music, and the world's literature. $\mathrm{He}$ was a member of the Bohemian Royal Society of Science, the Bohemian Academy of Science and Art, the Ministerial Institute for the Examination of Medicinal Matters, and of the State Hygienic Council, etc.

\section{BOHUslav Brauner.}

WE regret to announce the following deaths:

William J. Green, a pioneer in horticultural in vestigations and for many years horticulturalist at the Ohio Experiment Station, aged seventy-six years.

A. Witz, formerly professor of physics in the Catholic University of Lille, corresponding member of the Paris Academy of Sciences, who was known for his work on thermodynamics and on internal combustion engines, on January 25 , aged seventy-seven years.

$$
\text { NO. 2946, VOL. II } 7 \text { ] }
$$

